\title{
[Special Feature]
}

\section{Exotic Seeds on the Feathers of Migratory Birds on a Stopover Island in Korea}

\author{
Chang-Yong Choi, Hyun-Young Nam, Hee-Young Chae*
}

Migratory Birds Center, National Park Research Institute, Korea National Park Service, Shinan County, Jeonnam Province 535-916, Korea

\begin{abstract}
Migratory birds, by crossing significant ecological barriers, carry and may subsequently introduce exotic seeds into new ecological zones during period of migration. The study of epizoochory, which includes seed dispersal by adhesion to bird feathers, has been relatively neglected compared to the study of seed dispersal by frugivores. To determine whether exotic seeds are being imported to stopover islands by migrating birds, and to estimate the quantity of seeds of exotic species being introduced, we examined migratory birds that were captured in mist nets for attached exotic plant diaspores in 2008 and 2009 on Hongdo Island, Korea. From a total of 3,947 birds examined, we found exotic seeds of Japanese Chaff Flowers (Achyranthes japonica) attached to three species of migratory birds (0.08\%; Eurasian Bittern Botaurus stellaris, Swinhoe's Rail Coturnicops exquisitus and Oriental Turtle Dove Streptopelia orientalis). Despite the low occurrence of $A$. japonica seeds on the external parts of birds, the results suggest that migratory birds may be potential dispersing agents for $A$. japonica, a species that is currently threatening native ecosystems on many islands in Korea.
\end{abstract}

Key words: epizoochory, Japanese Chaff Flower (Achyranthes japonica), seed dispersal, Hongdo Island

\section{INTRODUCTION}

Seed dispersal is the process of departure of seeds away from the parent plant (Howe and Smallwood 1982). Because plants have relatively limited mobility, external agents are often involved in the transport of plant fruits and seeds. Although some plants with explosive fruits or creeping diasporas have the ability to self-disperse their seeds, the major dispersal agents for most plant species are water, wind, and animals (Howe and Smallwood 1982). Among these agents, animals can disperse seeds in a variety of ways. For example, seeds can be dispersed by scatter-hoarding birds, mammals, and ants (Sorensen 1986). Moreover, endozoochory or the dispersal of seeds through the digestive tract of frugivores, that consume fruits and swallow seeds, isa common and welldocumented mutualistic interaction between animals and plants subsequently dispersing seeds (Howe and Smallwood 1982, Sorensen 1986, Jordano 1995, Fukui
2003). However, seed dispersal by adhesion on animal fur and feathers, known as epizoochory, is also a distinctive dispersal mechanism, because epizoochorus fruits or seeds do not provide the dispersing agent with a nutritional or energetic reward (Sorensen 1986).

Many researchers have focused on the ecological functions of endozoochory and the nature of mutualistic interactions between animal dispersers and plants (e.g., Jordano 1995, Fukui 2003), while epizoochory has only been investigated to a limited extent (Sorensen 1986). However, epizoochorus seed dispersal seems to be the more important mechanism on islands because seeds dispersed by external adhesion have the potential for longer distance dispersal than do frugivores or winddispersed seeds (Vivian-Smith and Stiles 1994). At present, most evidence for epizoochorus seed dispersal is anecdotal or is concentrated on terrestrial mammals; only a few quantitative studies have focused on avian dispersers (Sorenson 1986, Vivian-Smith and Stiles 1994). In Korea, several studies have reported seed dispersal

*Corresponding author: Phone: +82-61-246-3115, e-mail: hychae7700@hanmail.net 


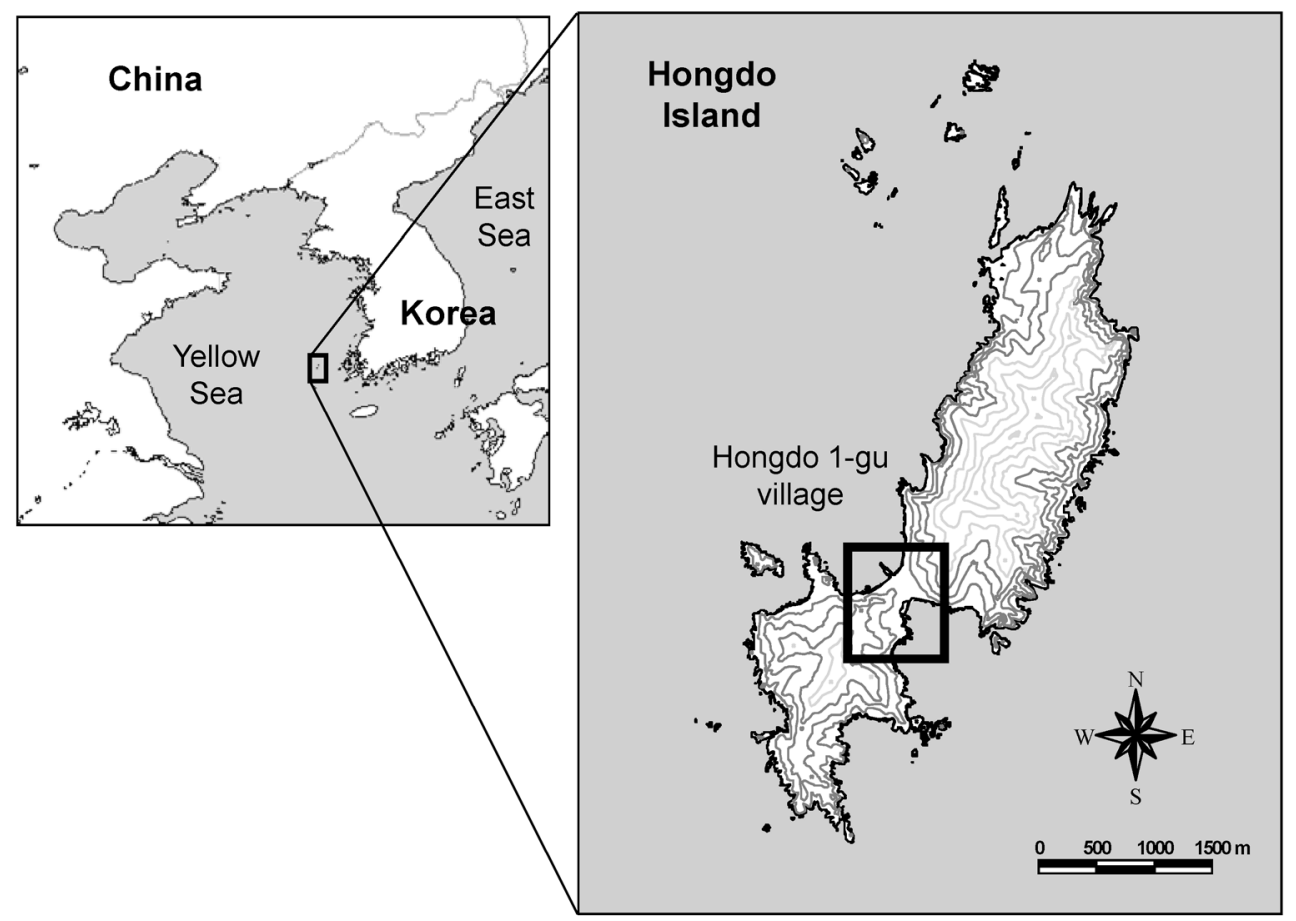

Fig. 1. Study area (Hongdo 1-gu village) on Hongdo Island, Shinan-gun, Jeonnam Province, Korea.

following passage through bird digestive systems (You et al. 1994, Choi and Chae 2007); however, to our knowledge there have been no reports of adhesive seed dispersal by birds.

Rose and Polis (2000) suggested five major types of interactions involving migratory and transient species on islands: predation, parasite and pathogen transmission, competition, zoogeomorphology, and cascading events. Among the migratory animal taxa, birds may act as particularly efficient dispersers of exotic seeds by traveling long distances and crossing significant ecological barriers such as seas and deserts. Therefore, avian migrants are thought to be responsible for the introductions of many exotic plants and may initiate cascading events on isolated islands by dispersing seeds (Vivian-Smith and Stiles 1994, Rose and Polis 2000).

In this study, we examined patterns of seed adhesion on the external parts of migrating birds that stopover on Hongdo Island to determine whether exotic seeds are being imported to stopover islands in Korea by adhesion to birds and to estimate the quantity of exotic seed being imported to these islands by migratory birds.

\section{MATERIALS AND METHODS}

\section{Study Area}

We conducted surveillance for epizoochorus diasporas at Hongdo 1-gu on Hongdo Island, Shinan-gun, Jeonnam Province, Republic of Korea. Hongdo Island (N 34 41', E $125^{\circ} 11^{\prime}$ ) is located $115 \mathrm{~km}$ from the southwestern part of the Korean Peninsula (Fig. 1). The island is an important stopover site for migratory birds during their migratory crossing of the Yellow Sea between Korea and China.

\section{Epizoochorus Diaspore Surveillance}

In 2008 and 2009, we set three mist nets $(2.5 \mathrm{~m} \times 12$ $\mathrm{m}$; mesh sizes: 32 and $38 \mathrm{~mm}$ ) daily from 07:00 to 18:00 to capture migratory birds on Hongdo Island. Birds trapped from March to December were ringed, measured, and then released following the banding scheme of the Korean National Park Migratory Birds Center (NPMBC). We examined all birds captured for plant seeds on their external parts before their release, and collected samples of the seeds for subsequent species- level identification.

\section{RESULTS}

We trapped and examined a total of 3,947 birds from 117 species on Hongdo Island from March to December in 2008 and 2009. In 2008, plant diaspores were found attached to only two of 1,777 birds examined: one Eurasian Bittern (Botaurus stellaris) and one Swinhoe's Rail (Coturnicops exquisitus). Eighteen diaspores were attached to the nape, back, and crural feathers of the 

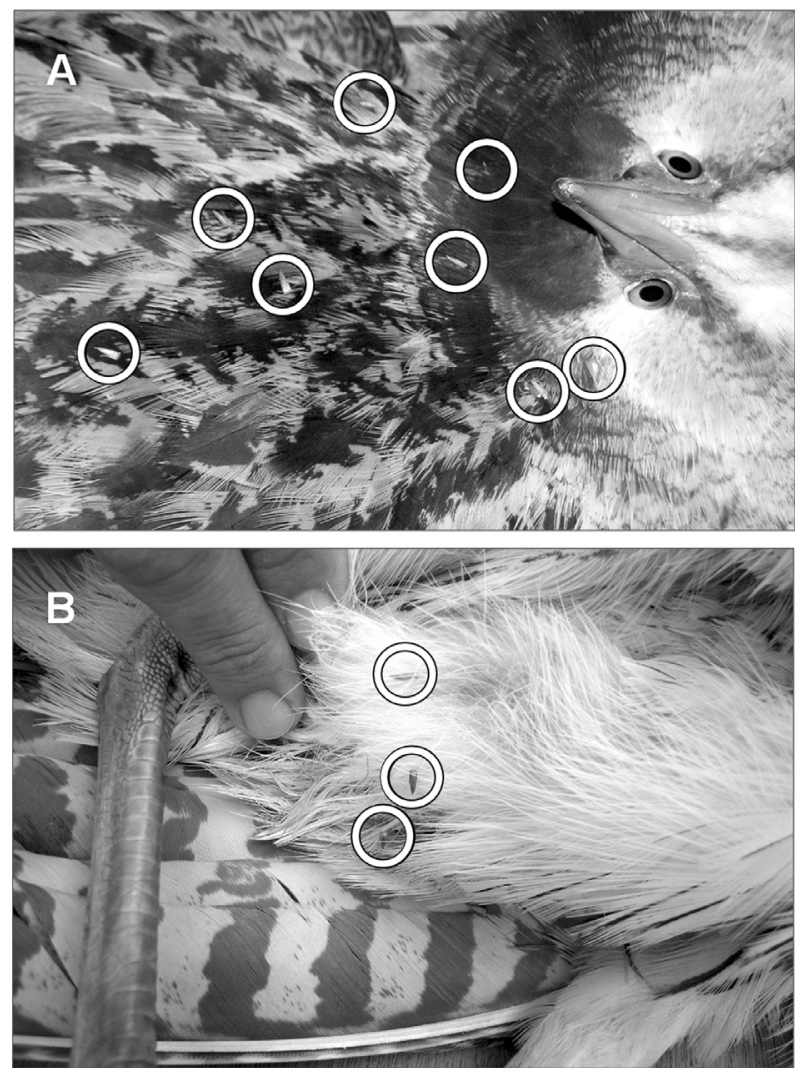

Fig. 2. Seeds of the Japanese Chaff Flower (Achyranthes japonica) attached on (A) back and (B) crural feathers of a Eurasian Bittern (Botaurus stellaris).

bittern, which was captured on 1 November 2008 (Fig. 2 ), and one diaspore was attached to the lore of the rail, which was captured on 2 November 2008 (Fig. 3). All of the diaspores found on these two migratory birds in 2008 were seeds of Japanese Chaff Flowers (Achyranthes japonica). In 2009, of the 2,170 birds examined, only one Oriental Turtle Dove (Streptopelia orientalis) captured in December bore a single seed of A. japonica on its tail feather.

\section{DISCUSSION}

The Japanese Chaff Flower (Achyranthes japonica) is a common perennial herb widely distributed in Korea, China, and Japan, and is used in traditional medicines and as a functional food additive due to its reported antibiotic and physiological effects (Jung et al. 2008). Although A. japonica is a native species in mainland Korea, it is considered an invasive species for many Korean islands. Over the past several decades, A. japonica has been introduced by feral domestic goats (Capra hircus) and humans onto islands where breeding colonies

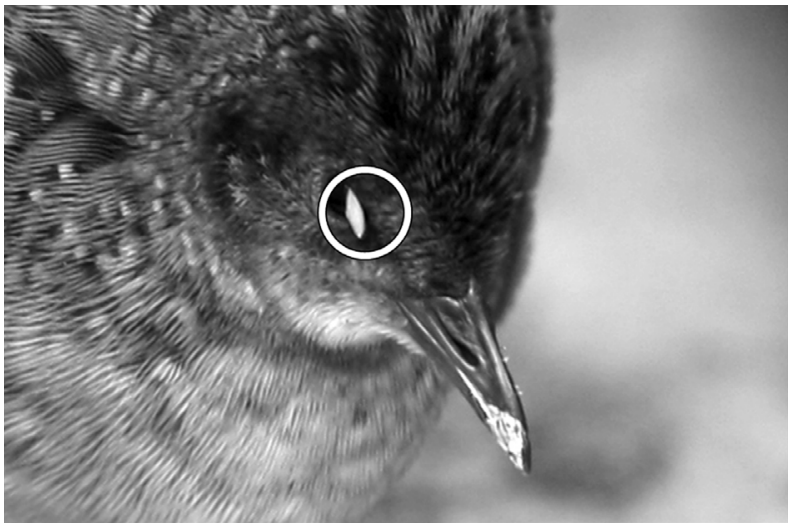

Fig. 3. A seed of the Japanese Chaff Flower (Achyranthes japonica) attached on the lore of a Swinhoe's Rail (Coturnicops exquisitus).

of seabirds occur, particularly the Swinhoe's Storm Petrel (Oceanodroma monorhis) (Lee et al. 2009). It competes with native herbs and increases mortality and breeding failure rates among seabirds on the affected islands (Lee et al. 2009).

Our evaluation of epizoochory by birds on a migratory stopover island, confirmed that autumn migrating birds can bear seeds of the exotic plant, A. japonica. Eurasian Bitterns and Swinhoe's Rails, two of the bird species that bore seeds on their feathers in this study, are both wading birds often observed near grasslands, rice paddies, marshes, and wetlands (Lee et al. 2000), areas where A. japonica is typically found. The Oriental Turtle Dove, one individual of which was found carrying a seed in December 2009, is also a ground-feeding species. Although we have no information about the origins of the seeds found on the birds in this study, they have increased opportunities for contact with A. japonica during the autumn fruiting season which occurs prior to their departure from the mainland on their southward migration. Particularly, Eurasian Bitterns and Swinhoe's Rails migrate significant distances from breeding areas in Russia to wintering ranges in southern China (Lee et al. 2000), and could therefore disperse seeds of A. japonica to remote islands far from existing stands of the plant in mainland Korea.

Seeds of Achyranthes aspera have been transported by seabirds such as noddies (Anous spp.) and terns (Sterna spp.) to Aldabra Atoll in the Indian Ocean (Diamond 1979). Our observations suggest that some birds, especially wading birds (e.g., bitterns, egrets, herons, and rails) and ground-feeding non-passerines, may also transport exotic A. japonica to stopover islands through epizoochory. However, only $0.08 \%$ of the birds that 
we examined here carried exotic diaspores, and only small numbers of diaspores were attached to the birds. Moreover, no passerines, which are the most abundant migrants in the study area, bore seeds on their plumage, which suggests that ground-dwelling or wading birds may be more important agents of epizoochorus seed dispersal due to their habitats and relatively larger body sizes. Previous studies of external seed loads have also suggested a more important role of seabirds (Diamond 1979) and waterfowls (Vivian-Smith and Stiles 1994) than passerines. Therefore, our results suggest that dispersal of exotic plant seeds via avian epizoochory occurs infrequently on stopover islands in Korea.

We conclude that migratory birds can bear, and may act as dispersers of seeds of exotic plants to stopover islands in Korea. Our study confirmed that feathers of three migrating non-passerines bore seeds of the exotic plant, A. japonica, an invasive species that is threatening native vegetations and breeding seabird colonies on remote islands. Because both the rate of occurrence of $A$. japonica seeds on the examined birds and the numbers of diaspores per affected individual were low, the rate of seed dispersal by migratory birds via epizoochory is probably low; epizoochory by birds may be less effective than seed dispersal by adhesion to humans or other large mammals. However, the possibility of transport of exotic seeds on migratory birds should not be overlooked, because infrequent visitors on islands may initiate cascading events that can influence island community structure and species succession with effects from the base of the island food web upward (Rose and Polis 2000) and because epizoochory has the potential to result in long distance seed dispersal (Vivian-Smith and Stiles 1994). Our findings reveal a new possible mechanism of A. japonica dispersal by birds, that should be considered by researchers and conservation managers attempting to eradicate exotic species and to restore native vegetation and seabird breeding colonies in Korea.

\section{ACKNOWLEDGEMENTS}

We thank the members of the Migratory Birds Center, National Park Research Institute, Korea National Park Service, for their bird banding surveys and field works. Dr. Terry A. Klein, Dr. Joon-Seok Chae, and Dr. Heung-Chul Kim also contributed to this study through constructive advice.

\section{LITERATURE CITED}

Choi CY, Chae HY. 2007. Effects of bird ingestion on seed dispersal and germination of the Elaeagnus macrophylla. Jour Korean For Soc 96: 633-638. (in Korean with English summary)

Diamond AW. 1979. Dynamic ecology of Aldabran seabird communities. Phil Trans R Soc Lond B 286: 231-240.

Fukui A. 2003. Relationship between seed retention time in bird's gut and fruit characteristics. Ornithol Sci 2: 41-48.

Herrera CM. 1984. Adaptations to frugivory of Mediterranean avian seed dispersers. Ecology 65: 609-617.

Howe HF, Smallwood J. 1982. Ecology of seed dispersal. Annu Rev Ecol Syst 13: 201-228.

Jordano P. 1995. Angiosperm flesh fruits and seed dispersers: a comparative analysis of adaptation and constraints in plant-animal interactions. Am Nat 145: 163-191.

Jung SM, Choi SI, Park SM, Heo TR. 2008. Synergistic antimicrobial effect of Achyranthes japonica Nakai extracts and Bifidobacterium supernatants against Clostridium difficile. Food Sci Biotechnol 17: 402-407.

Lee KG, Ko GN, Jegal GM, Park CA. 2009. Impacts of introduced plants on the breeding of Swinhoe's Storm Petrels (Oceanodroma monorhis) and conservation activities in Shinan-gun County, Korea. In Seabirds in Danger: Invasive Species and Conservation of Island Ecosystem (Chae HY, Choi CY, Nam HY, eds). Publication of the National Park Migratory Birds Center, Shinan, pp 19-36. http://www.npmbc.or.kr/symposium/2009/2009_ proceeding.pdf

Lee WS, Koo TH, Park JY. 2000. A Field Guide to the Birds of Korea. LG Evergreen Foundation, Seoul.

Moermond TC, Denslow JS. 1983. Fruit choice in neotropical birds. J Anim Ecol 52: 407-418.

Rose MD, Polis GA. 2000. On the insularity of islands. Ecography 23: 693-701.

Sorensen AE. 1981. Interactions between birds and fruit in a temperate woodland. Oecologia 56: 242-249.

Sorensen AE. 1986. Seed dispersal by adhesion. Annu Rev Ecol Syst 17: 443-463.

Vivian-Smith G, Stiles EW. 1994. Dispersal of salt marsh seeds on the feet and feathers of waterfowl. Wetlands 14: 316319.

You YH, Kim KB, An CS, Song SD, Kim JH. 1994. Establishment by seeds and maintenance by ramets in Elaeagnus umbellate population. Korean J Ecol 17: 203-211. (in Korean with English summary)

(Received on December 26, 2009; Accepted on January 25, 2010) 